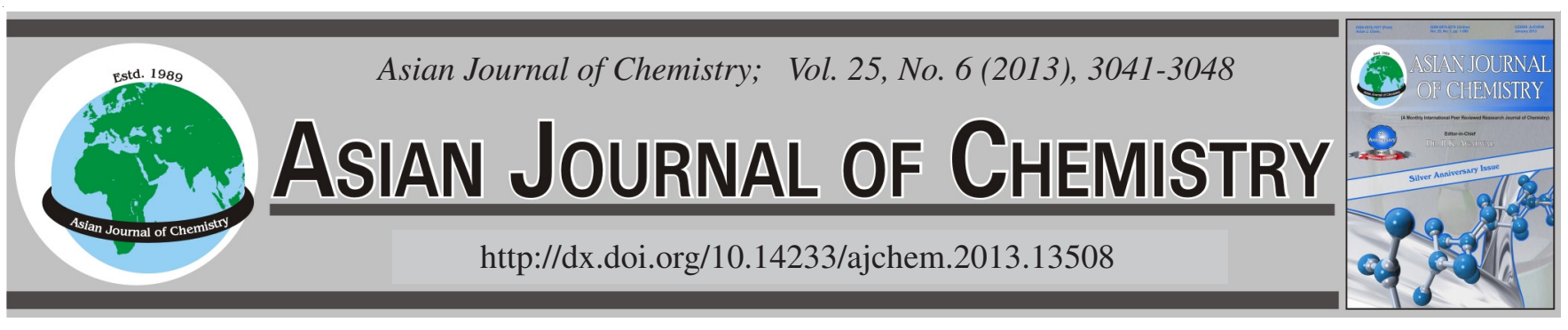

\title{
Removal of Arsenic from Aqueous Solution by Fe(III)- Impregnated Sorbent Prepared from Sugarcane Bagasse
}

\author{
Meina Liang ${ }^{1,2}$, Yinian Zhu ${ }^{2, *}$, Dunqiu Wang ${ }^{2}$, Hua Zhang ${ }^{1}$, Zongqiang Zhu ${ }^{1}$ and Zhihong Chen ${ }^{2}$
}

${ }^{1}$ College of Light Industry and Food Engineering, Guangxi University, Nanning 530004, Guangxi Province, P.R. China

${ }^{2}$ College of Environmental Science and Engineering, Guilin University of Technology, Jian-Gan Road 12, Guilin 541004, P.R. China

*Corresponding author: Fax: +86 773 5895330; Tel: +86 773 5897016; E-mail: zhuyinian@163.com

(Received: 24 January 2012;

Accepted: 12 December 2012)

AJC-12515

\begin{abstract}
An $\mathrm{Fe}(\mathrm{III})$-impregnated adsorbent was prepared from sugarcane bagasse and $\mathrm{FeCl}_{3}$ solution via carbonization/activation in a muffle furnace at $500{ }^{\circ} \mathrm{C}$ for $4 \mathrm{~h}$. The sorption removal of arsenic from aqueous solution by the prepared sorbent was then studied in a batch system. In order to investigate the mechanism of sorption, this paper employs the four different kinetic models to fit to the experimental data. The studies showed that within $0.5 \mathrm{~h}$ this sorbent was able to remove $96.96,95.99$ and $94.60 \%$ of arsenic from water containing an initial arsenic concentration of 1,2 and $4 \mathrm{mg} / \mathrm{L}$, respectively. At initial $\mathrm{pH}$ from 3 to 12 , the arsenic concentration of treated solution was lesser than $5 \mu \mathrm{g} / \mathrm{L}$ at the initial arsenic concentration of $2 \mathrm{mg} / \mathrm{L}$, it was far below the U.S. EPA standard (10 $\mu \mathrm{g} / \mathrm{L})$. The pseudo-secondorder kinetic model generated the best fit to the experimental data with regression coefficients $\mathrm{R}^{2}=1.0000$.
\end{abstract}

Key Words: Fe(III)-impregnation, Sorbent, Sugarcane bagasse, Arsenic, Sorption removal.

\section{INTRODUCTION}

Arsenic compounds are ubiquitous in the environment and potentially toxic to human. Arsenic pollution is mainly caused by natural and human activity. Water is one of the most important media through which arsenic enters into the human body $^{1,2}$. Arsenic is regulated in drinking water and a maximum allowable limit, known as a maximum contaminant level, has been set for it. For many years, the maximum contaminant level was $50 \mu \mathrm{g} / \mathrm{L}$ (ppb). Some people who drink water containing arsenic in excess of the maximum contaminant level over many years could experience skin damage or problems with their circulatory system and may have an increased risk of getting cancer.

During the 1990s, however, it was determined that this level was too high to provide for maximum public health protection and world health organization (WHO) recommended maximum contaminant level of arsenic in drinking water 10 $\mu \mathrm{g} / \mathrm{L}$ in $1993^{3}$. The U.S. environmental protection agency decided to lower the maximum contaminant level to $10 \mu \mathrm{g} / \mathrm{L}$ in 2006. Meanwhile, this value also had been reduced from 50 to $10 \mu \mathrm{g} / \mathrm{L}$ by China since 2007. Appropriate purification techniques are required to meet these strict regulations. The treatment progresses for arsenic wastewater mainly include coagulation-precipitation, ion exchange, membrane filtration and adsorption ${ }^{4}$. Adsorption process was generally applied in water purification and wastewater treatment for its lower cost, better commercial availability and less environmental impact. The adsorbents mainly include activated carbons, $\alpha-\mathrm{Al}_{2} \mathrm{O}_{3}$, montmorillonite modified with polymeric $\mathrm{Al} / \mathrm{Fe}$, amberlite resins loaded metal, etc. ${ }^{5,6}$.

Sorption has been considered as an alternative approach for removal of arsenic since the sorption process can be operated simply, produces little sludge. Considerable attention has been paid to the development of effective and low-cost sorbents and to evaluate their capacity for removal of arsenic. If low cost alternative sorbents can be developed, it would be beneficial to the environment and have attractive commercial value. In these aspects, various materials such as activated sludge, iron oxide, granular ferric hydroxide, rice hush silica and red mud have been investigated for arsenic sorption ${ }^{7-12}$.

Activated carbon is a black solid substance resembling granular or powder charcoal and is widely used as sorbents in waste water and gas treatments ${ }^{13,14}$. Despite its prolific use in environmental protection, activated carbon remains an expensive material. In recent years, research interest in the production of low-cost alternatives to activated carbon has grown ${ }^{15}$. Agricultural wastes have emerged as a better choice. Though raw agricultural wastes can be used as sorbents without further treatment, activation could enhance their sorption capacity. The production of activated carbons from agricultural wastes convert undesired, surplus agricultural waste, of which billions 
of kilograms are produced annually, to useful valuable sorbents ${ }^{16}$.

Sugarcane bagasse is the fibrous waste left after the extraction of sugar juice from crushed cane. Sugarcane refining generates a large volume of residue called bagasse. Sugarcane bagasse in its natural state is a poor sorbent of organic compound such as sugar colourants and metal ions ${ }^{17,18}$. Since bagasse is a highly carbonaceous agricultural byproduct, a natural outlet would be to use bagasse as a feedstock in the manufacture of activated carbons, which can then be used in the wastewater treatment process. Bagasse is reported as a suitable resource for preparation of activated carbon ${ }^{19-22}$.

In the present paper, an $\mathrm{Fe}(\mathrm{III})$-impregnated sorbent was prepared from sugarcane bagasse and $\mathrm{FeCl}_{3}$ and then was used to investigate the sorption removal of arsenic from aqueous solution. Studies concerning the effects of contact time, temperature, amount of sorbent, initial arsenic concentration and solution $\mathrm{pH}$ on the adsorption were experimentally studied. Experimental data were analyzed by using kinetic equations. The characteristic parameters for each model have been determined.

\section{EXPERIMENTAL}

Preparation of the $\mathrm{Fe}(\mathrm{III})$-impregnated sorbent: The reagents $\mathrm{FeCl}_{3} \cdot 6 \mathrm{H}_{2} \mathrm{O}$ and cetyltrimethyl ammonium bromide (CTMAB) were bought from Country Medicine Group, Shanghai, China. Sugarcane bagasse was collected from a sugar industry, Guangxi, China. The bagasse was left to dry in oven at $80{ }^{\circ} \mathrm{C}$ for $24 \mathrm{~h}$, then it was cut into small pieces and sieved to an average particle size of $5 \mathrm{~mm} .1 \mathrm{~mol} / \mathrm{L} \mathrm{FeCl}_{3}$ solution, 0.05 $\mathrm{mol} / \mathrm{L}$ cetyltrimethyl ammonium bromide (CTMAB) solution, $1 \%$ and $10 \%(\mathrm{v} / \mathrm{v})$ ammonia solutions were prepared from chemical reagents of analytical grade and ultra-pure water.

$800 \mathrm{~mL}$ Ultra-pure water and $100 \mathrm{~mL} 0.05 \mathrm{~mol} / \mathrm{L} \mathrm{CTMAB}$ solution were added into a $2 \mathrm{~L}$ beaker and heated to the boiling point. Then, under stirring, $100 \mathrm{~mL} 1 \mathrm{~mol} / \mathrm{L} \mathrm{FeCl}_{3}$ solution was added into the beaker slowly to obtain red brown colloid solution. $50 \mathrm{~g}$ Dried bagasse was added to the colloid solution and mixed immediately. After immersed for $24 \mathrm{~h}$, the mixture of the colloid solution and bagasse was adjusted to $\mathrm{pH}=7.4$ with $10 \%$ or $1 \%(\mathrm{v} / \mathrm{v})$ ammonia solution by using the automatic potentiometric titration (Metrohm 848 Titrino Plus). Under this condition, a bagasse $/ \mathrm{Fe}(\mathrm{OH})_{3}$ mixture was formed in the suspended solution. The suspended solid was filtered and dried in oven at $105-110^{\circ} \mathrm{C}$ for $24 \mathrm{~h}$. Finally, the bagasse/ $\mathrm{Fe}(\mathrm{OH})_{3}$ solid was carbonized/activated in a muffle furnace at $500{ }^{\circ} \mathrm{C}$ for $4 \mathrm{~h}$ to get the $\mathrm{Fe}$ (III)-impregnated sorbent. In order to obtain a powder with a particle size smaller than $0.124 \mathrm{~mm}$ (120 mesh), the sample was ground and sifted.

\section{Sorption experiments}

Effects of sorption conditions: The experiments were carried out in a set of plastic centrifuge tubes $(100 \mathrm{~mL})$ by agitating desired amounts of the Fe(III)-impregnated sorbent powder in $50 \mathrm{~mL}$ arsenic solutions of desired concentration and $\mathrm{pH}$ with an isothermal shaker $\left(25,35\right.$ or $\left.45^{\circ} \mathrm{C}\right)$ at the agitation speed of $200 \mathrm{rpm}$ for $48 \mathrm{~h}$ to reach equilibrium of the solid-solution mixture. After centrifuged at $4000 \mathrm{rpm}$ for $5 \mathrm{~min}$, the supernatant fluid of all samples was filtered through
$0.45 \mu \mathrm{m}$ micro-pore membrane and aqueous arsenic concentrations were determined.

Effect of $\mathrm{pH}$ was studied by adjusting the initial $\mathrm{pH}$ of arsenic solutions using diluted $\mathrm{HNO}_{3}$ and $\mathrm{NaOH}$ solutions $(\mathrm{pH}$ $=2,3,4,5,6,7,8,9,10,11,12)$ and the solutions were agitated with $0.3 \mathrm{~g} / 50 \mathrm{~mL}$ sorbent for $2 \mathrm{mg} / \mathrm{L}$ arsenic concentrations at $25^{\circ} \mathrm{C}$. Eleven initial concentrations for arsenic (1, 2, 4, 6, 8, 10, 12, 14, 16, 18 and $20 \mathrm{mg} / \mathrm{L}$ ) were employed for the study of initial concentration effect on sorption at 25, 35 or $45^{\circ} \mathrm{C}$. Effect of sorbent amount was studied with different amount of sorbent $(0.05,0.10,0.15,0.20,0.25,0.30,0.35$ and $0.40 \mathrm{~g}$ ) and $50 \mathrm{~mL} 5 \mathrm{mg} / \mathrm{L}$ arsenic solutions at $25^{\circ} \mathrm{C}$.

Sorption kinetics: Kinetic studies were carried out in a set of plastic centrifuge tubes $(100 \mathrm{~mL})$ at constant temperatures $\left(25,35\right.$ or $\left.45^{\circ} \mathrm{C}\right)$, by shaking $0.3 \mathrm{~g}$ of the $\mathrm{Fe}(\mathrm{III})$ impregnated sorbent powder in $50 \mathrm{~mL}$ arsenic solutions $(1,2$ and $4 \mathrm{mg} / \mathrm{L}$; initial $\mathrm{pH}=7$ ) in each capped plastic centrifuge tube at the stirring speed of $200 \mathrm{rpm}$. The aqueous samples were taken from different conical flasks at different time intervals of $0.5,1,1.5,3,6,9,12,18,24,30,36,42$ and $48 \mathrm{~h}$, respectively. All samples were centrifuged and filtered through a $0.45 \mu \mathrm{m}$ membrane filter in order to remove the carbon fines. And then, the total arsenic concentrations in aqueous solutions were determined.

Detection method: The total arsenic concentrations in aqueous solutions were determined by Atomic Absorption Spectrometer (PE AAnalyst 700). The sorbent was characterized by using X-ray diffractometer (XRD, X'Pert PRO), the morphology was analyzed by scanning electron microscopy (SEM, Jeol JSM-6380LV).

\section{RESULTS AND DISCUSSION}

XRD and SEM: BET surface area and the BJH desorption surface area of the prepared Fe(III)-impregnated sorbent were determined to be $26.79 \mathrm{~m}^{2} / \mathrm{g}$ and $32.58 \mathrm{~m}^{2} / \mathrm{g}$, respectively. The average pore diameter and the total pore volume were derived from the BJH method to be $12.25 \mathrm{~nm}$ and $0.0201 \mathrm{~cm}^{3}$ / g. All the major peaks in the XRD pattern from the sorbent could be clearly seen and identified as belonging to standard hematite $\left(\alpha-\mathrm{Fe}_{2} \mathrm{O}_{3}\right)(00-033-0664)$. This confirms the formation of hematite $\left(\alpha-\mathrm{Fe}_{2} \mathrm{O}_{3}\right)$ during the sorbent preparation (Fig. 1). The SEM images of the prepared sorbent are showed in Fig. 2. Particles of different size and different shape could be observed for the sugarcane bagasse used in the experiment. The particle sizes of carbons and hematite $\left(\alpha-\mathrm{Fe}_{2} \mathrm{O}_{3}\right)$ in the prepared sorbent were $400 \mathrm{~nm}^{-1} \mu \mathrm{m}$ and $<500 \mathrm{~nm}$, respectively.

Contact time and temperature: The sorption rate expressed by $\mathrm{d} q / \mathrm{d} t$ shows how much sorbate can be sorbed from the liquid phase onto the sorbent within a unit of time. In a diagram depicting the $\mathrm{q}_{\mathrm{t}} \mathrm{t}$ relationship, the slope at each point of the curve represents the instantaneous sorption rate $\mathrm{d} q / \mathrm{d} t^{23}$. The effect of the contact time on the sorption kinetics is shown in Fig. 3, in terms of the $\mathrm{q}_{\mathrm{t}} \mathrm{t}$ relationship. The arsenic concentration decreased rapidly with the contact time and this confirmed strong interactions between the arsenic and the sorbent. In other words, the sorption capacity increased with contact time. Fig. 3 reveals that the amount of arsenic sorbed $(\mathrm{mg} / \mathrm{g})$ increased with the contact time until it gradually 
approaches the equilibrium state due to the continuous decease in the driving force $\left(\mathrm{q}_{\mathrm{e}}-\mathrm{q}_{\mathrm{t}}\right)$. The amount of arsenic sorbed and the concentration of arsenic in the liquid phase remained almost constant, after sorption for 540, 720, 1440 min at $25^{\circ} \mathrm{C}$ and $\mathrm{pH} 7$ with the initial arsenic concentration of 1,2 and $4 \mathrm{mg} / \mathrm{L}$, respectively.

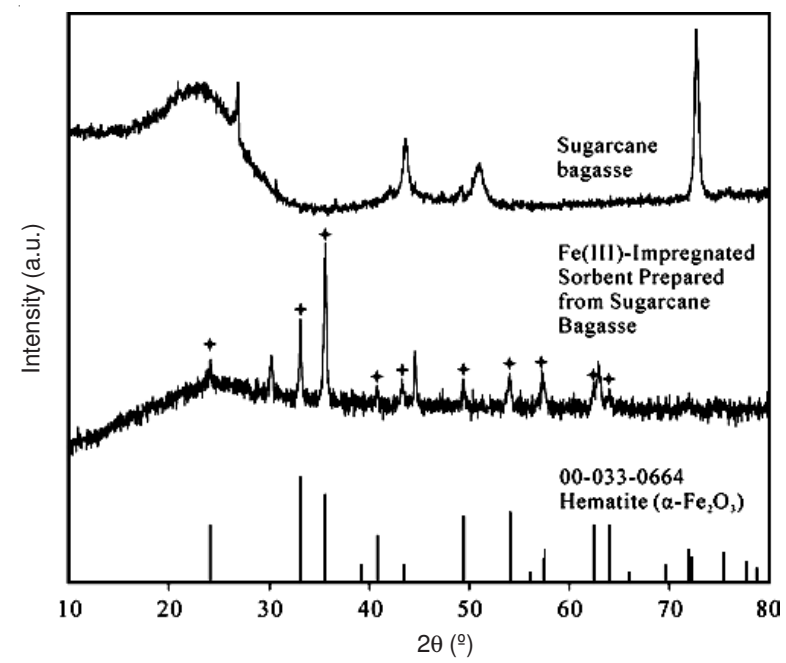

Fig. 1. XRD result of the sugarcane bagasse and the Fe(III)-impregnated sorbent prepared from sugarcane bagasse

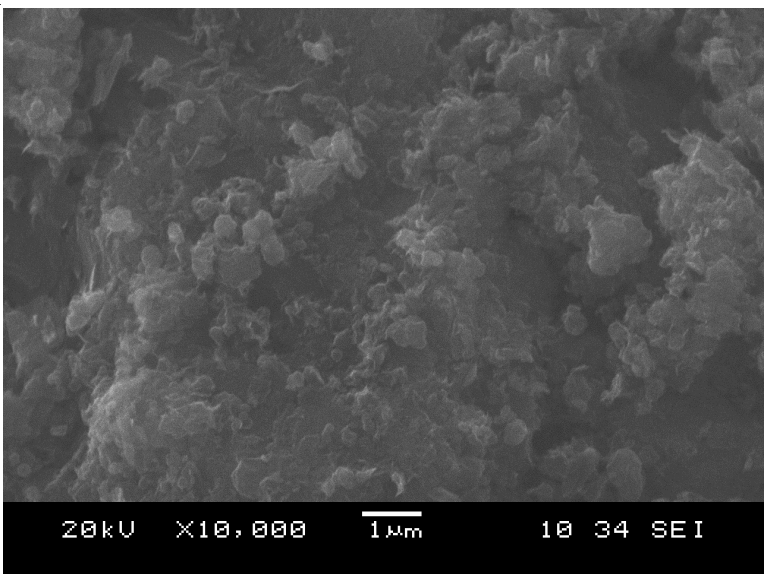

Fig. 2. SEM result of the Fe(III)-impregnated sorbent prepared from sugarcane bagasse

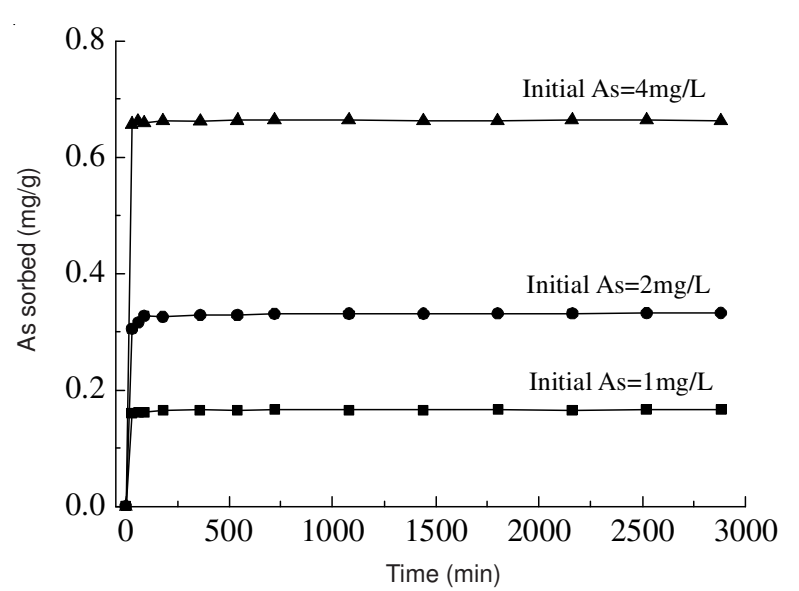

Fig. 3. Effect of contact time on arsenic sorption onto the Fe(III)impregnated sorbent prepared from sugarcane bagasse (initial $\mathrm{pH}$ $=7$, amount of sorbent $0.3 \mathrm{~g} / 50 \mathrm{~mL}, 25^{\circ} \mathrm{C}$ )
It is also shown that within $0.5 \mathrm{~h}$ this sorbent was able to remove $96.96,95.99$ and $94.60 \%$ of arsenic from water containing an initial arsenic concentration of 1, 2 and $4 \mathrm{mg} / \mathrm{L}$, respectively. For an initial arsenic concentration of $1 \mathrm{mg} / \mathrm{L}$ at $25^{\circ} \mathrm{C}$ and $\mathrm{pH} 7$, the maximum amount of arsenic was sorbed within the first $9 \mathrm{~h}$ at an average sorption rate of 0.000307 $\mathrm{mg} /(\mathrm{g} \min )$ (99.90\% of total amount of arsenic sorbed). A similar trend was observed for the initial arsenic concentrations of 2 and $4 \mathrm{mg} / \mathrm{L}$. The contact time between sorbate and the sorbent is of significant importance in sorption. In physical sorption, most of the sorbate species are sorbed within a short interval of contact time. However, strong chemical binding of the sorbate with sorbent requires a longer contact time for the attainment of equilibrium. Available sorption studies in literature reveal also that the uptake of sorbate species is fast at the initial stages of the contact period and thereafter, it becomes slower near the equilibrium ${ }^{24}$. The initial rapid uptake of sorbate species may be due to large numbers of available vacant sites on the sorbent surface at the initial stage ${ }^{25}$.

Fig. 4 showed the effect of temperature on the amount of arsenic sorbed. It is evident that with the increase in temperature the amount of arsenic sorbed are decreased when it reached sorption equilibrium. This agrees with the exothermic nature of adsorption process. It seems that the diffusion process (intra particle transport-pore diffusion) has less control over the adsorption of arsenic as the diffusion-controlled adsorption is endothermic in nature ${ }^{26}$. Recent publications support intensely surface precipitation as an additional and simultaneously acting removal mechanism for arsenic on iron oxides ${ }^{27,28}$. With the increase in temperature the mobility of ions will increase, as a result surface precipitation will decrease. With the increase in temperature the stability of the bonds between the active sites of the Fe(III)-impregnated sorbent prepared from sugarcane bagasse and arsenic moiety decreases. Due to these reasons the amount of arsenic sorbed decreases with the increase in temperature. As arsenic is more strongly bound with the active sites in case of the Fe(III)-impregnated sorbent prepared from sugarcane bagasse, hence, the amount of arsenic sorbed is greater in case of the Fe(III)-impregnated sorbent prepared from sugarcane bagasse.

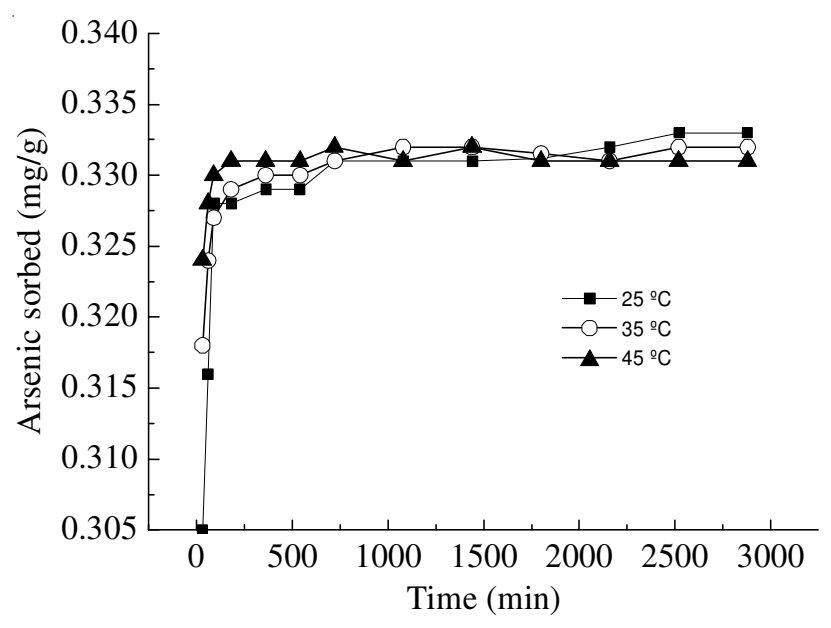

Fig. 4. Effect of temperature on arsenic sorption onto the Fe(III)impregnated sorbent prepared from sugarcane bagasse (initial concentration $2 \mathrm{mg} / \mathrm{L}, \mathrm{pH}=7$, amount of sorbent $0.3 \mathrm{~g} / 50 \mathrm{~mL}$ ) 
Amount of sorbent: Keeping the same initial arsenic concentration and initial $\mathrm{pH}$ and contact time constant at $25^{\circ} \mathrm{C}$, the sorption of arsenic onto the Fe(III)-impregnated sorbent was studied by varying the sorbent quantity in the test solution (Fig. 5). Fig. 5 showed that the increase in sorption with amount of sorbent can be attributed to increased sorbent surface area and availability of more sorption sites. But unit sorption decreased with increase in amount of sorbent. This may be attributed to overlapping or aggregation of sorbent surface area available to arsenic and an increase in diffusion path length ${ }^{29}$. The actual amount of arsenic sorbed per unit mass of sorbent decreased with increasing sorbent quantity in test solution from 1.76 to $0.25 \mathrm{mg} / \mathrm{g}$. On the contrary, the percentage of arsenic removed from solution increased continuously from 88.61 to $99.60 \%$ with increasing amount of sorbent from 50 to 150 $\mathrm{mg}$ in $50 \mathrm{~mL}$ test solution. But the removal efficiency did not increase with the increasing amount of sorbent when the amount of sorbent was greater than $150 \mathrm{mg}$ in $50 \mathrm{~mL}$ test solution. The solution $\mathrm{pH}$ decreased with increasing sorbent quantity in test solution from 1 to $8 \mathrm{~g} / \mathrm{L}$.

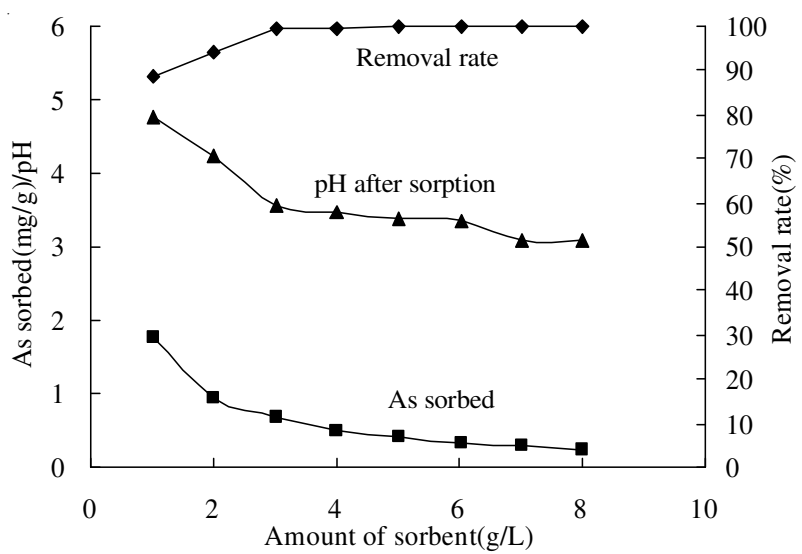

Fig. 5. Effect of amount of sorbent on arsenic sorption onto the Fe(III)impregnated sorbent prepared from sugarcane bagasse(initial concentration $2 \mathrm{mg} / \mathrm{L}, \mathrm{pH}=7$, temp. $25^{\circ} \mathrm{C}$ )

Initial arsenic concentration: The kinetics dependencies were also measured for various initial arsenic concentrations at 25,35 and $45^{\circ} \mathrm{C}$, whereas the other experimental parameters were kept constant. The dependencies of the amount of arsenic sorbed, $\mathrm{q}_{\mathrm{e}}$ and the removal percentage versus the initial concentration are shown in Fig. 6. The overall trend for different temperatures was similar, i.e., with increasing arsenic concentrations in test solution from $1 \mathrm{mg} / \mathrm{L}$ to $6 \mathrm{mg} / \mathrm{L}$, the actual amount of arsenic sorbed per unit mass of sorbent increased from $0.17 \mathrm{mg} / \mathrm{g}$ to $1.00 \mathrm{mg} / \mathrm{g}$ at $25^{\circ} \mathrm{C}$, at $35^{\circ} \mathrm{C}$, at $45^{\circ} \mathrm{C}$. But with increasing arsenic concentrations in test solution from 6 $\mathrm{mg} / \mathrm{L}$ to $20 \mathrm{mg} / \mathrm{L}$, the actual amount of arsenic sorbed per unit mass of sorbent increased from $1.00 \mathrm{mg} / \mathrm{g}$ to $2.92 \mathrm{mg} / \mathrm{g}$ at 25 ${ }^{\circ} \mathrm{C}$, from $1.00 \mathrm{mg} / \mathrm{g}$ to $3.13 \mathrm{mg} / \mathrm{g}$ at $35^{\circ} \mathrm{C}$ and from $1.00 \mathrm{mg} / \mathrm{g}$ to $3.20 \mathrm{mg} / \mathrm{g}$ at $45^{\circ} \mathrm{C}$, which confirmed strong physical and chemical interactions between arsenic and the Fe(III)-impregnated sorbent. If the results are expressed in percentage of arsenic removed from solution, the percent sorption decreased continuously from $99.79 \%$ to $87.78 \%$ at $25^{\circ} \mathrm{C}, 99.76 \%$ to $94.23 \%$ at $35^{\circ} \mathrm{C}$ and $99.81 \%$ to $96.18 \%$ at $45^{\circ} \mathrm{C}$, with increase in initial arsenic concentration from $6 \mathrm{mg} / \mathrm{L}$ to $20 \mathrm{mg} / \mathrm{L}$.

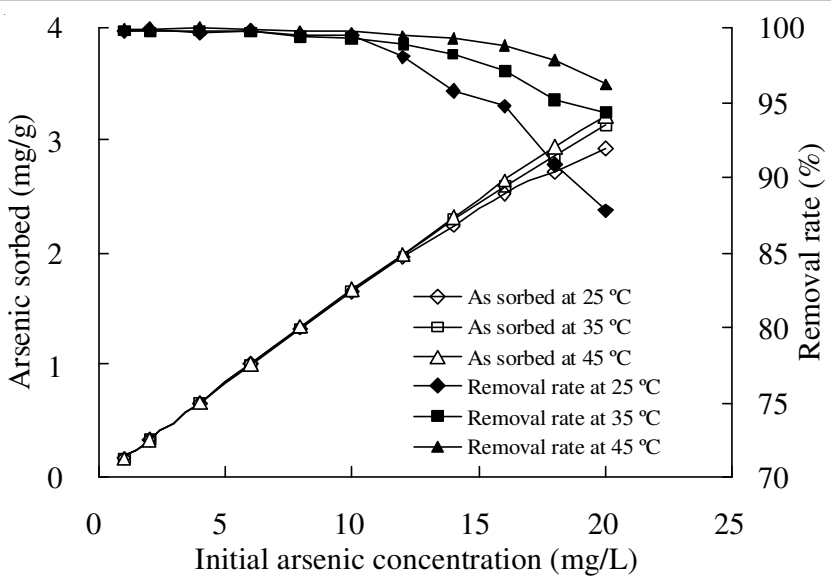

Fig. 6. Effect of initial concentration on arsenic sorption onto the Fe(III)impregnated sorbent prepared from sugarcane bagasse (initial $\mathrm{pH}$ $=7$, amount of sorbent $0.3 \mathrm{~g} / 50 \mathrm{~mL}$ )

pH of the solution: The $\mathrm{pH}$ of the solution plays an important role in the whole sorption process, influencing not only the solution arsenic chemistry, but also the surface charge of the sorbent $\mathrm{t}^{30}$. Effect of initial solution $\mathrm{pH}$ on the sorption of arsenic is shown in Fig.7. Arsenic upon dissolution formed arsenic anions in solution. The sorption of these charged arsenic groups onto the sorbent surface was primarily influenced by the surface charge on the sorbent which, in turn, was influenced by $\mathrm{pH}$ of the solution ${ }^{30}$. After sorption, the solution $\mathrm{pH}$ decreased under both acid and basic conditions. High initial $\mathrm{pH}$ favoured the sorption of arsenic onto the Fe(III)-impregnated sorbent. As the $\mathrm{pH}$ increased from 2 to 12 , the sorption capacity increased from 0.330 to $0.333 \mathrm{mg} / \mathrm{g}$ and the corresponding removal rate increased from 99.0 to $99.9 \%$. At the same time, as the initial $\mathrm{pH}$ increased from 3 to 12 , the arsenic concentration of treated solution was lesser than $5 \mu \mathrm{g} / \mathrm{L}$, it was far below the U.S. environmental protection agency standard $(10 \mu \mathrm{g} / \mathrm{L})$. The sorption capacity and the corresponding removal rate were also negatively correlated to the solution $\mathrm{pH}$ at equilibrium (Fig. 8). It is obviously that both of them increased with the increasing solution $\mathrm{pH}$ at equilibrium.

The $\mathrm{pH}$ shown to be one of the key variables for removal of arsenic. The maximum removal was achieved at $\mathrm{pH}-4$ by activated $\mathrm{CO}_{2}$-neutralized red mud ${ }^{12}$ and the arsenic removal

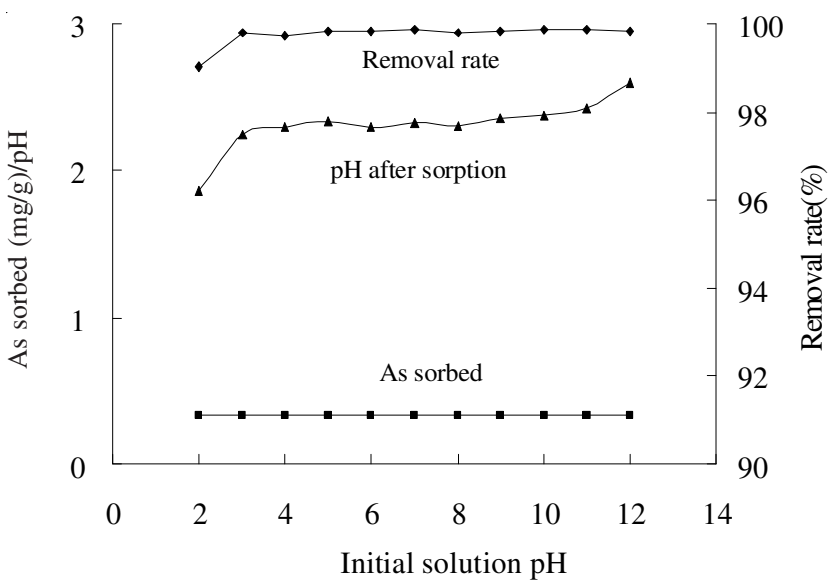

Fig. 7. Effect of initial $\mathrm{pH}$ on arsenic sorption onto the Fe(III)-impregnated sorbent prepared from sugarcane bagasse (initial concentration 2 $\mathrm{mg} / \mathrm{L}$, amount of sorbent $0.3 \mathrm{~g} / 50 \mathrm{~mL}$, temp. $25^{\circ} \mathrm{C}$ ) 


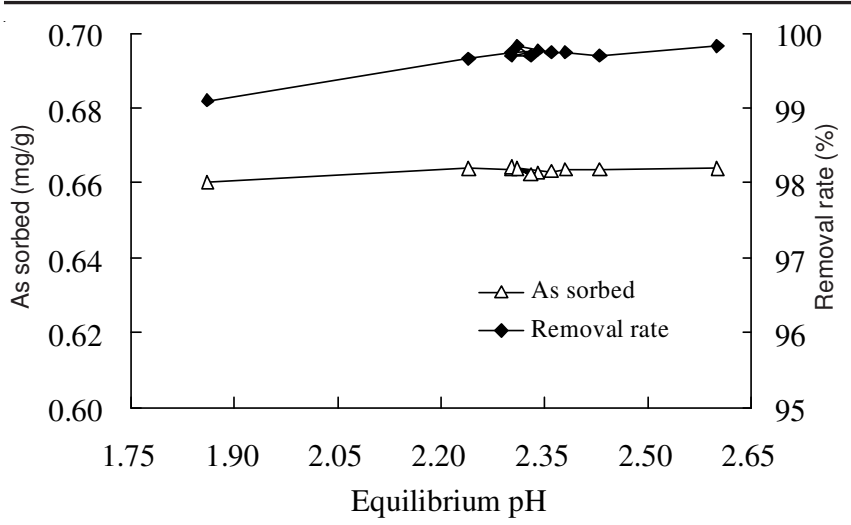

Fig. 8. Effect of equilibrium $\mathrm{pH}$ on arsenic sorption onto the Fe(III)impregnated sorbent prepared from sugarcane bagasse (initial concentration $4 \mathrm{mg} / \mathrm{L}$, amount of sorbent $0.3 \mathrm{~g} / 50 \mathrm{~mL}$, temp. $25^{\circ} \mathrm{C}$ )

rate maintained close to $100 \%$ at $\mathrm{pH}$ 2-6 by iron-impregnated granular activated carbon ${ }^{31}$. Speciation and charge of the anionic sorbate arsenic influence the sorption onto metal oxide surfaces, i.e. removal of arsenic is $\mathrm{pH}$ dependent. The sorption of arsenic onto hematite is considered to be dominated by complexation between surface groups and the sorbing molecules. Depending on $\mathrm{pH}$, the hematite surface sites react as acid or base, inducing a pH-dependent surface charge causing electrostatic interactions with the surrounding aqueous phase. Below its $\mathrm{pH}_{\mathrm{PZC}}$ (point zero of charge), hematite is a positively-charged sorbent. Arsenic is an anionic sorbate in monovalent $\left(\mathrm{H}_{2} \mathrm{AsO}_{4}{ }^{-}\right)$and divalent $\left(\mathrm{HAsO}_{4}{ }^{2-}\right)$ forms. Hematite bear higher positive charged at low $\mathrm{pH}$ values, thus, sorbed higher amounts of arsenic. There is no clear correlation between surface area and arsenic sorption capacity for hematite. It has been found that sorption capacity depends on crystal morphology ${ }^{32,33}$.

Sorption kinetics: The study of sorption equilibrium and kinetics is essential in supplying the fundamental information required for the design and operation of sorption equipments for wastewater treatment. In order to investigate the mechanism of sorption, this paper employs the four different kinetic models, namely the pseudo-first-order equation, the modified pseudo-first-order equation, the pseudo-second-order equation and the intra-particle diffusion model.

Pseudo-first-order kinetic model: The equation corresponding to the pseudo-first-order kinetic model is the following differential form ${ }^{34}$ :

$$
\frac{\mathrm{dq}_{\mathrm{t}}}{\mathrm{dt}}=\mathrm{k}_{\mathrm{l}}\left(\mathrm{q}_{\mathrm{e}}-\mathrm{q}_{\mathrm{t}}\right)
$$

Integrating this for the boundary condition $\mathrm{q}_{\mathrm{e}}=0$ at $\mathrm{t}=0$ and $\mathrm{q}_{\mathrm{t}}=\mathrm{q}_{\mathrm{t}}$ at $\mathrm{t}=\mathrm{t}$, gives:

$$
\ln \frac{\mathrm{q}_{\mathrm{e}}}{\mathrm{q}_{\mathrm{e}}-\mathrm{q}_{\mathrm{t}}}=\mathrm{k}_{\mathrm{l}} \mathrm{t}
$$

where, $\mathrm{q}_{\mathrm{e}}$ and $\mathrm{q}_{\mathrm{t}}$ refer to the amount of arsenic sorbed $(\mathrm{mg} / \mathrm{g})$ at equilibrium and at any time, $\mathrm{t}(\mathrm{min})$, respectively and $\mathrm{k}_{1}$ is the equilibrium rate constant of the pseudo-first-order sorption $\left(\mathrm{min}^{-1}\right)$. Eqn. (2) can be rearranged to obtain a linear form:

$$
\ln \left(\mathrm{q}_{\mathrm{e}}-\mathrm{q}_{\mathrm{t}}\right)=\ln \mathrm{q}_{\mathrm{e}}-\mathrm{k}_{1} \mathrm{t}
$$

The plot of $\ln \left(\mathrm{q}_{\mathrm{e}}-\mathrm{q}_{\mathrm{t}}\right)$ against $\mathrm{t}$ should give a straight line with slope $k_{1}$ and intercept $\ln \mathrm{q}_{\mathrm{e}}$ (Fig. 9). The values of $\mathrm{k}_{1}$ and $\mathrm{q}_{\mathrm{e}}$ at different initial arsenic concentrations are presented in Table-1. As seen in Table-1, the correlation coefficient value $\mathrm{R}^{2}$ for arsenic sorption onto the $\mathrm{Fe}$ (III)-impregnated adsorbent changed in the range of $0.8442-0.8704$. These results have shown that the experimental data do not well agree with the pseudo-first-order kinetic model.

Modified pseudo-first-order kinetic model: The pseudofirst-order equation represented by Eqn. (1) is modified through the modification of its rate constant ${ }^{23}$. Denote the rate constant in the modified pseudo first- order rate equation by $\mathrm{K}_{1}$ $\left(\mathrm{min}^{-1}\right)$, the following equation is proposed:

$$
\mathrm{k}_{1}=\mathrm{K}_{1} \frac{\mathrm{q}_{\mathrm{e}}}{\mathrm{q}_{\mathrm{t}}}
$$

As $\mathrm{q}_{\mathrm{t}}<\mathrm{q}_{\mathrm{e}}$, the above equation implies that the rate constant $\mathrm{k}_{1}$ is minimum when equilibrium is reached.
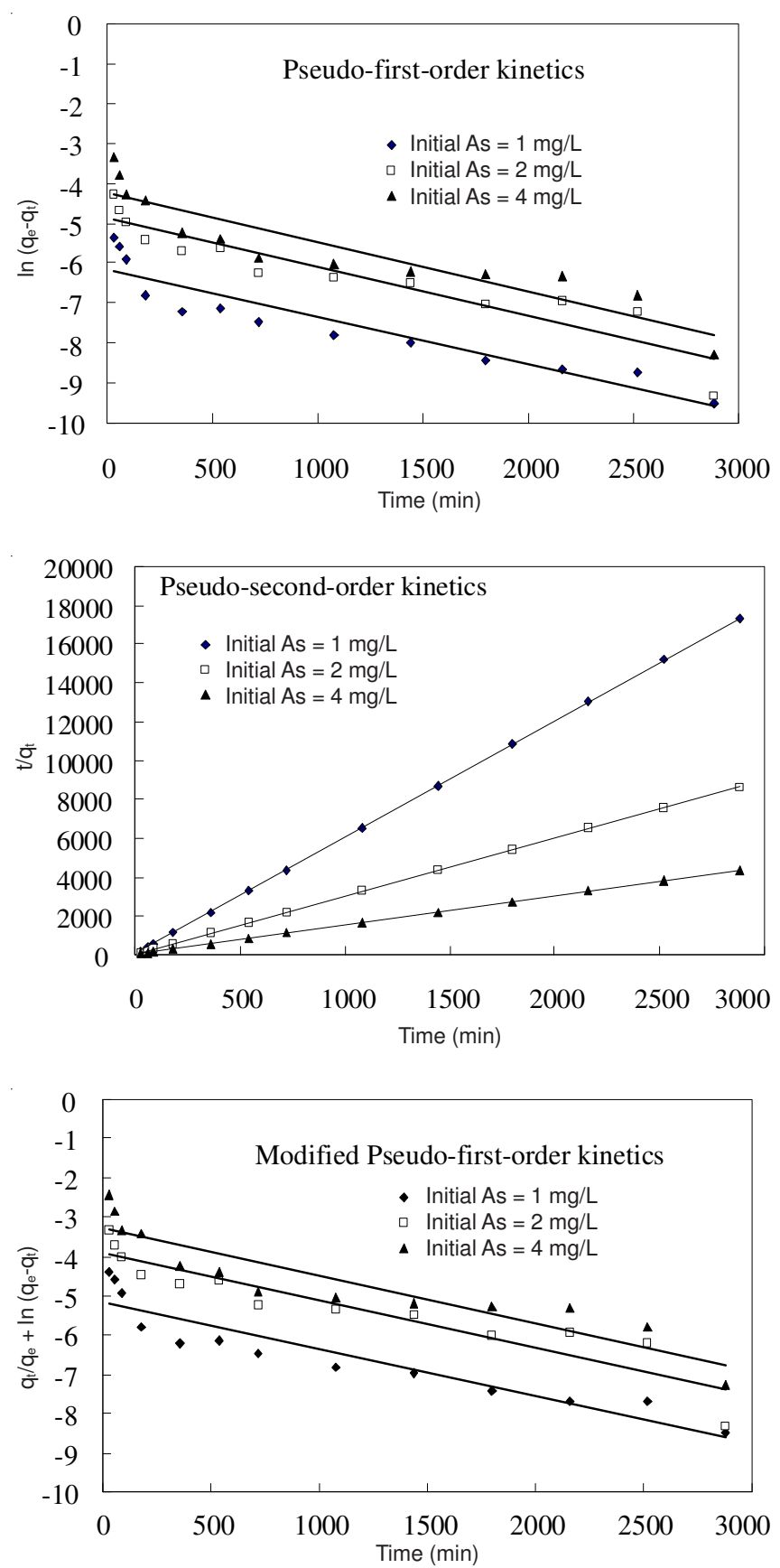


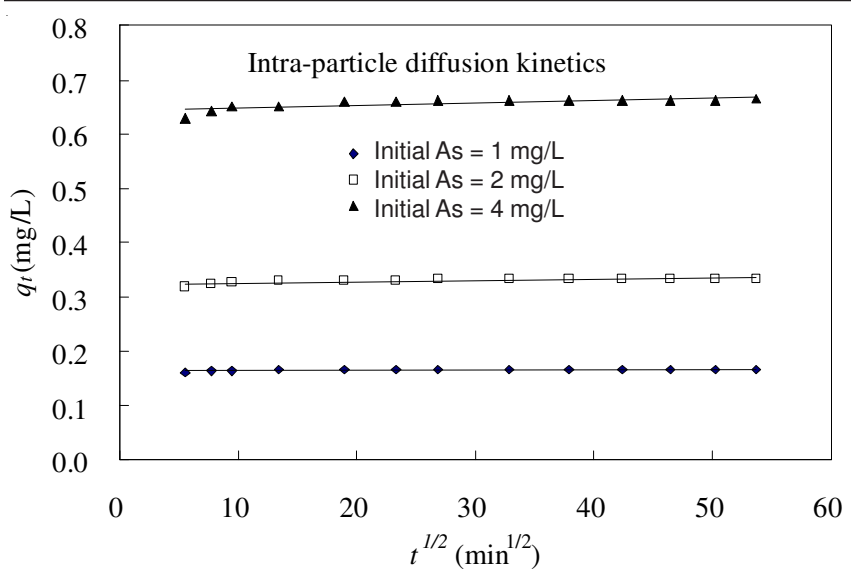

Fig. 9. Kinetics for arsenic sorption onto the Fe(III)-impregnated sorbent prepared from sugarcane bagasse (initial $\mathrm{pH}=7$, amount of sorbent $0.3 \mathrm{~g} / 50 \mathrm{~mL}, 25^{\circ} \mathrm{C}$ )

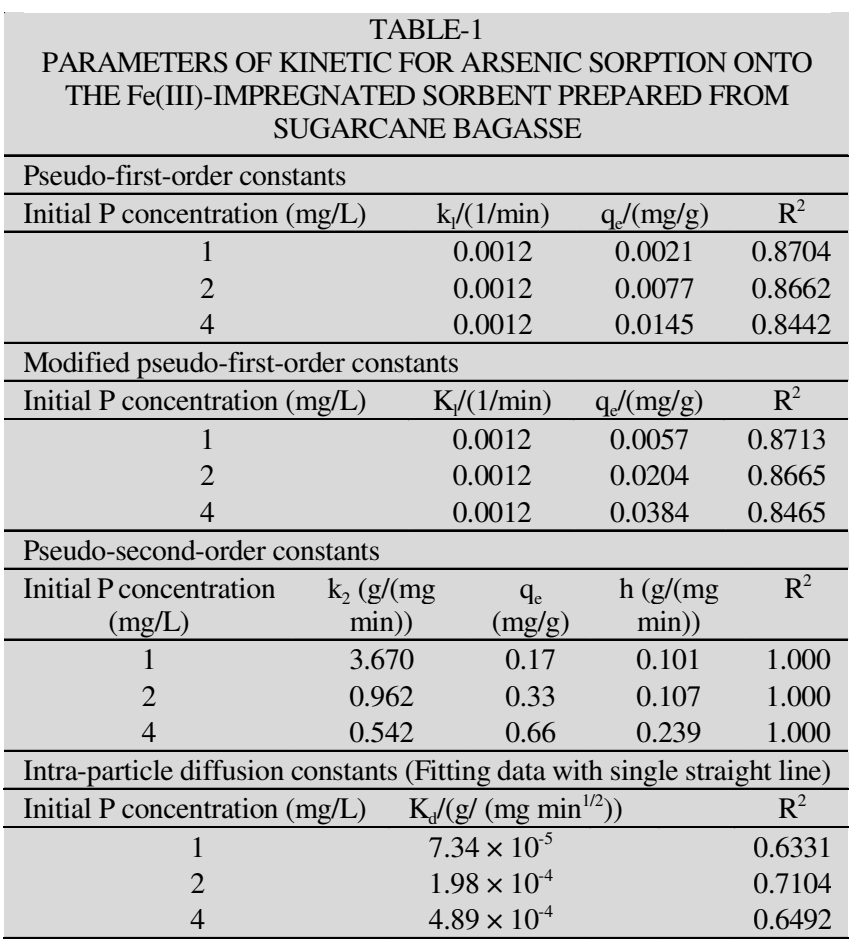

The modified pseudo-first-order rate equation can be derived as follows:

$$
\frac{\mathrm{dq}_{\mathrm{t}}}{\mathrm{d}_{\mathrm{t}}}=\mathrm{K}_{1} \frac{\mathrm{q}_{\mathrm{e}}}{\mathrm{q}_{\mathrm{t}}}\left(\mathrm{q}_{\mathrm{e}}-\mathrm{q}_{\mathrm{t}}\right)
$$

Eqn. (5) can be rearranged into:

$$
-\mathrm{dq}_{\mathrm{t}}+\frac{\mathrm{q}_{\mathrm{e}} \mathrm{dq}_{\mathrm{t}}}{\left(\mathrm{q}_{\mathrm{e}}-\mathrm{q}_{\mathrm{t}}\right)}=\mathrm{K}_{\mathrm{l}} \mathrm{q}_{\mathrm{e}} \mathrm{dt}
$$

Integrate eqn. (6) over time $t \in(0, t)$, during which the solid phase concentration increases from zero to $\mathrm{q}_{\mathrm{t}}$, the following algebraic equation can be obtained:

$$
\frac{\mathrm{q}_{\mathrm{t}}}{\mathrm{q}_{\mathrm{e}}}+\ln \left(\mathrm{q}_{\mathrm{e}}-\mathrm{q}_{\mathrm{t}}\right)=\ln \left(\mathrm{q}_{\mathrm{e}}\right)-\mathrm{K}_{\mathrm{l}} \mathrm{t}
$$

If the sorption process follows the modified pseudo-first order kinetic model represented by eqn. (7), a plot of $\mathrm{q}_{\mathrm{t}} / \mathrm{q}_{\mathrm{e}}+$ $\ln \left(\mathrm{q}_{\mathrm{e}}-\mathrm{q}_{\mathrm{t}}\right)$ against $\mathrm{t}$ should be a straight line (Fig. 9). The values of $\mathrm{K}_{1}$ and $\mathrm{q}_{\mathrm{e}}$ at different concentration are presented in Table- 1 .
As seen in Table-1, the correlation coefficient values for arsenic sorption onto the $\mathrm{Fe}$ (III)- impregnated sorbent changed in the range of $0.8465-0.8713$. This result has shown that the experimental data did not fit well with the modified pseudofirst-order kinetic model.

Pseudo-second order kinetic model: The equation corresponding to the pseudo-second-order kinetic model is the following ${ }^{35}$ :

$$
\frac{\mathrm{dq}_{\mathrm{t}}}{\mathrm{dt}}=\mathrm{k}_{2}\left(\mathrm{q}_{\mathrm{e}}-\mathrm{q}_{\mathrm{t}}\right)^{2}
$$

Integrating this for the boundary condition $\mathrm{t}=0, \mathrm{q}_{\mathrm{e}}=0, \mathrm{t}$ $=\mathrm{t}, \mathrm{q}_{\mathrm{t}}=\mathrm{q}_{\mathrm{t}}$ gives:

$$
\frac{1}{q_{e}-q_{t}}=\frac{1}{q_{t}}+k_{2} t
$$

where, $\mathrm{k}_{2}$ is the equilibrium rate constant of the pseudosecond-order sorption $[\mathrm{g} /(\mathrm{mg} \mathrm{min})]$. Eqn (9) can be arranged to obtain a linear form:

$$
\frac{\mathrm{t}}{\mathrm{q}_{\mathrm{t}}}=\frac{1}{\mathrm{k}_{2} \mathrm{q}_{\mathrm{e}}^{2}}+\frac{1}{\mathrm{q}_{\mathrm{e}}} \mathrm{t}
$$

The initial sorption rate, $\mathrm{h}(\mathrm{mg} /(\mathrm{g} \min ))$, as $\mathrm{t}=0$ can be defined $^{16}$ :

$$
\mathrm{h}=\mathrm{k}_{2} \mathrm{q}_{\mathrm{e}}^{2}
$$

where, the initial sorption rate $(\mathrm{h})$, the equilibrium sorption capacity $\left(\mathrm{q}_{\mathrm{e}}\right)$ and the second-order constants $\mathrm{k}_{2}(\mathrm{~g} /(\mathrm{mg} \min )$ ) can be determined experimentally from the slope and intercept of plot t/q versus t (Fig.9). Calculated correlations are closer to unity for second-order kinetics model $\left(\mathrm{R}^{2}=1.0000\right)$; therefore the sorption kinetics could well be approximated more favourably by second-order kinetic model for arsenic sorption onto the $\mathrm{Fe}$ (III)-impregnated adsorbent. The $\mathrm{k}_{2}$ and $\mathrm{h}$ values are calculated from Fig. 9 to be $0.542-3.67 \mathrm{~g} /(\mathrm{mg} \mathrm{min})$ and 0.101-0.239 $\mathrm{g} /(\mathrm{mg} \mathrm{min})$, respectively (Table-1). This result has shown that the experimental data fit well with the modified pseudo-second order kinetic model.

Intra-particle diffusion kinetic model: The arsenic sorption is governed usually by either the liquid phase mass transport rate or the intra-particle mass transport rate. Hence diffusive mass transfer is incorporated into the sorption process $^{30}$. Intra-particle diffusion model assumes that the film diffusion is negligible and intra-particle diffusion is the only rate-controlling step, which is usually true for well-mixed solutions. An empirically found functional relationship, common to the most sorption processes, is that the uptake varies almost proportionally with $\mathrm{t}^{1 / 2}$, the Weber-Morris plot, rather than with the contact time $\mathrm{t}^{25}$.

$$
\mathrm{q}_{\mathrm{t}}=\mathrm{K}_{\mathrm{d}} \mathrm{t}^{1 / 2}+\mathrm{C}
$$

where, $K_{d}$ is the intra-particle diffusion rate constant $[\mathrm{mg} /(\mathrm{g}$ $\left.\min ^{1 / 2}\right)$ ]. According to eqn. (12), a plot of $\mathrm{q}_{\mathrm{t}}$ versus $\mathrm{t}^{1 / 2}$ should be a straight line with a slope $\mathrm{K}_{\mathrm{d}}$ and intercept $\mathrm{C}$ when sorption mechanism follows the intra-particle diffusion process. Values of intercept give an idea about the thickness of boundary layer, i.e., larger the intercept with greater is the boundary layer effect. In Fig. 9 plot of mass of arsenic adsorbed per unit mass of adsorbent, $\mathrm{q}_{\mathrm{t}}$ versus $\mathrm{t}^{1 / 2}$ is presented for arsenic. The linear 
plots are attributed to the macro pore diffusion that is the accessible sites of sorption. This is attributed to the instantaneous utilization of the most readily available adsorbing sites on the adsorbent surface ${ }^{25}$. The values of $\mathrm{K}_{\mathrm{d}}$ as obtained from the slope of straight lines was $7.34 \times 10^{-5}-4.89 \times 10^{-4} \mathrm{mg} /(\mathrm{g}$ $\left.\min ^{1 / 2}\right)$. As seen in Table-1, the correlation coefficient value $\mathrm{R}^{2}$ for arsenic sorption onto the Fe(III)-impregnated adsorbent changed in the range of $0.6331-0.7104$. These results have shown that the experimental data do not well agree with the intra-particle diffusion kinetic model.

Comparison of the applicability of different kinetic models: Among the four kinetic models, the pseudo-secondorder equation generates the best fit to the experimental data of the three investigated sorption systems at the initial arsenic concentrations of 1,2 and $4 \mathrm{mg} / \mathrm{L}$ for the entire sorption period, with regression coefficients $\mathrm{R}^{2}=1.0000$ for the concentration range used in this study. The calculated $\mathrm{q}_{\mathrm{e}}$ values from the model were also in good agreement with the experimental values. This indicates that the pseudo-second-order equation is potentially a generalized kinetic model for sorption study. Kinetics of arsenic sorption onto the Fe(III)-impregnated adsorbent followed the pseudo-second order model, suggesting that the rate-limiting step may be chemical sorption ${ }^{36}$. This confirmed that sorption of arsenic takes place probably via surface exchange reactions until the surface functional sites are fully occupied; thereafter arsenic molecules diffuse into the adsorbent network for further interactions ${ }^{37}$.

The second best model to generate a good fit to the experiment is the modified pseudo-first-order kinetic model, followed by the pseudo-first-order kinetic model. For the modified pseudo-first-order kinetic model and the pseudo-first-order kinetic model, correlation coefficients were below 0.995 and the calculated $\mathrm{q}_{\mathrm{e}}$ were not equal to experimental $\mathrm{q}_{\mathrm{e}}$, suggesting the insufficiency of the model to fit kinetic data for the initial concentrations examined. After a short period, the experimental data deviated considerably from linearity.

It is worth noting that the low correlation coefficients shown in Table-1 do not necessarily mean that the intraparticle diffusion process is not the rate-controlling step. It is a mere indication that the intra-particle diffusion model does not apply to the investigated sorption systems ${ }^{23}$. This may be due to the following two reasons: first, the intra-particle diffusion model assumes infinite solution volume control, which implies that there is no change in solution concentration during the approach to equilibrium. This is only achieved when the product of the solution volume and solution concentration greatly exceeds the product of the adsorbent mass and the equilibrium sorption capacity of the adsorbent. Second, the intra-particle diffusion model is derived assuming a constant diffusivity $^{23}$. However, available studies have shown that the diffusivity of the investigated sorption systems depends on the solid phase concentration to a large extent. The two factors may have contributed to the less than satisfactory agreement between the experiment and the prediction by the intraparticle diffusion model ${ }^{38}$. Actually, the plots of the amount of arsenic sorbed versus $\mathrm{t}^{1 / 2}$ for intra-particle transport appeared to present a multilinearity which indicated that three steps occurred in the process (Fig. 9): (1) mass transfer across the external boundary layer film of liquid surrounding the outside of the particle; (2) adsorption at a site on the surface (internal or external) and the energy will depend on the binding process (physical or chemical); this step is often assumed to be extremely rapid; (3) diffusion of the sorbate molecules to an sorption site either by a pore diffusion process through the liquid filled pores or by a solid surface diffusion mechanism. The mechanism of sorption is generally considered to involve three steps, one or any combination of which can be the ratecontrolling mechanism ${ }^{39}$. It can be also observed that the plots did not pass through the origin; this was indicative of some degree of boundary layer control and this further showed that the intra-particle diffusion was not the only rate-limiting step, but other processes might control the rate of sorption ${ }^{30}$.

\section{Conclusion}

Arsenic sorption onto the Fe(III)-impregnated adsorbent was strongly influenced by several operational factors. The amount of arsenic sorbed increased with the contact time until it gradually approaches the equilibrium. The actual amount of arsenic sorbed per unit mass of adsorbent decreased from 1.76 to $0.25 \mathrm{mg} / \mathrm{g}$ with increasing sorbent amount from 50 to $400 \mathrm{mg}$ in $50 \mathrm{~mL}$ test solution. But the removal efficiency did not increase with the increasing sorbent amount when the sorbent amount was greater than $150 \mathrm{mg}$ in $50 \mathrm{~mL}$ test solution. With increasing arsenic concentrations in test solution from 1 to $20 \mathrm{mg} / \mathrm{L}$, the amount of arsenic sorbed increased from 0.17 to $2.92 \mathrm{mg} / \mathrm{g}$ at $25^{\circ} \mathrm{C}$, from 0.17 to $3.13 \mathrm{mg} / \mathrm{g}$ at $35^{\circ} \mathrm{C}$ and from 0.17 to $3.20 \mathrm{mg} / \mathrm{g}$ at $45^{\circ} \mathrm{C}$ and the corresponding removal rate decreased from 99.69 to $87.78 \%$ at $25^{\circ} \mathrm{C}$, from 99.73 to $94.23 \%$ at $35^{\circ} \mathrm{C}$ and from 99.91 to $96.18 \%$ at $45^{\circ} \mathrm{C}$. As the initial $\mathrm{pH}$ increased from 2 to 12 , the sorption capacity increased from 0.330 to $0.333 \mathrm{mg} / \mathrm{g}$ and the corresponding removal rate increased from 99.00 to $99.90 \%$. At the same time, as the initial $\mathrm{pH}$ from 3 to 12 , the arsenic concentration of treated solution is lesser than $5 \mu \mathrm{g} / \mathrm{L}$ at the initial arsenic concentration of $2 \mathrm{mg} / \mathrm{L}$, it is far below the U.S. Environmental Protection Agency Standard $(10 \mu \mathrm{g} / \mathrm{L})$. The sorption capacity and the corresponding removal rate were negatively correlated to the solution $\mathrm{pH}$ at equilibrium. The sorption capacity increased with the increase of sorption temperature.

The pseudo-second-order equation generated the best fit to the experimental data of the three investigated sorption systems at the initial arsenic concentrations of 1, 2 and $4 \mathrm{mg} / \mathrm{L}$ for the entire sorption period, with regression coefficients was $\mathrm{R}^{2}=1.000$ for the concentration range used in this study. The calculated $\mathrm{q}_{\mathrm{e}}$ of $0.17,0.33$ and $0.66 \mathrm{mg} / \mathrm{g}$ were equal to the actual values of the experiment. The $\mathrm{k}_{2}$ and $\mathrm{h}$ values were calculated to be $0.542-3.67 \mathrm{~g} /(\mathrm{mg} \mathrm{min})$ and $0.101-0.239 \mathrm{~g} /(\mathrm{mg} \mathrm{min})$, respectively. The experimental data do not well agree with the pseudo-first-order kinetic model, the modified pseudo-firstorder kinetic model and the intraparticle diffusion kinetic model.

\section{ACKNOWLEDGEMENTS}

The manuscript has greatly benefited from insightful comments by anonymous reviewers. The authors thank the Guangxi Key Laboratory of Environmental Engineering, Protection and Assessment for the research assistance and the financial supports from the Special Project of the National 
Water Pollution Control and Management of China (No. 2008ZX07317-02), the Provincial Natural Science Foundation of Guangxi (2011GXNSFF018003, 2011GXNSFA018013, 2012GXNSFDA053022 and GuiKeZhong-1298002-3).

\section{REFERENCES}

1. M.A. Khan and Y.-S. Ho, Asian J. Chem., 23, 1889 (2011).

2. P. Mondal, C.B. Majumder and B. Mohanty, J. Hazard. Mater., 137, 464 (2006).

3. WHO, Guidelines for Drinking Water quality, World Health Organization, Geneva, 41 (1993).

4. D. Mohan and J.C.U. Pittman, J. Hazard. Mater, 142, 1 (2007)

5. C.L. Chuang, M. Fan, M. Xu, R.C. Brown, S. Sung, B. Saha and C.P. Huang, Chemosphere, 61, 478 (2005).

6. A. Ramesh, H. Hasegawa, T. Maki and K. Ueda, Sep. Purif. Technol., 56, 90 (2007).

7. H.A. Andrianisa, A. Ito, A. Sasaki, M. Ikeda, J. Aizawa and T. Umita, Water Res., 42, 4809 (2008).

8. H. Zeng, M. Arashiro and D.E. Giammar, Water Res., 42, 4629 (2008).

9. E. Deliyanni and T.J. Bandosz, J. Hazard. Mater., 186, 667 (2011).

10. M. Badruzzaman, P. Westerhoff and D.R.U. Knappe, Water Res., 38, 4002 (2004).

11. K. Wantala, S. Sthiannopkao, B. Srinameb, N. Grisdanurak and K.W. Kim, Environ. Geochem. Health, 32, 261 (2010).

12. R.C. Sahu, R. Patel and B.C. Ray, J. Hazard. Mater., 179, 1007 (2010).

13. Z.G. Liu, F.S. Zhang and R. Sasai, Chem. Eng. J., 160, 57 (2010).

14. H. Hong, H. Kim, K. Baek and J. Yang, Desalination, 223, 221 (2008).

15. N.R. Khalili, M. Campbell, G. Sandi and J. Golas, Carbon, 38, 1905 (2000).

16. D. Mohan and K.P. Singh, Water Res., 36, 2304 (2002).

17. K. Qureshi, I. Bhatti, R. Kazi and A.K. Ansari, Int. J. Chem. Biol. Eng., 1, 145 (2008).

18. H. Boussarsar, B. Rogé and M. Mathlouthi, Bioresour. Technol., 100, 6537 (2009).
19. M. Ahmedna, W.E. Marshall and R.M. Rao, Bioresour. Technol., 71, 103 (2000).

20. O. Ioannidou and A. Zabaniotou, Renew. Sust. Energ. Rev., 11, 1966 (2007).

21. S.Y. Wong, Y.P. Tan, A.H. Abdullah and S.T. Ong, J. Phys. Sci., 20, 59 (2009).

22. P.C. Brandão, T.C. Souza, C.A. Ferreira, C.E. Hori and L.L. Romanielo, J. Hazard. Mater, 175, 1106 (2010).

23. X.Y. Yang and B. Al-Duri, J. Colloid Interf. Sci., 287, 25 (2005).

24. P. Mondal, C. Balomajumder and B. Mohanty, J. Hazard. Mater, 144, 420 (2007).

25. D. Kavitha and C. Namasivayam, Bioresour. Technol., 98, 14 (2007).

26. V.C. Srivastava, M.M. Swamy, I.D. Mall, B. Prasad and I.M. Mishra, Colloid. Surf., 272, 89 (2006).

27. S.R. Hinkle and D.J. Polette, Water-Resource Investigation Report 984205, US Department of the Interior, U.S. Geological Survey (1999).

28. A. Sperlich, A. Werner, A. Genz, G. Amy, E. Worch and M. Jekel, Water Res., 39, 1190 (2005).

29. H. Lata, V.K. Garg and R.K. Gupta, Dyes Pigm., 74, 653 (2007).

30. G. Crini, Dyes Pigm., 77, 415 (2008).

31. Q.G. Chang, W. Lin and W.C. Ying, J. Hazard. Mater., 184, 515 (2010).

32. R.M. Cornell and U. Schwertmann, The Iron Oxides: Structure, Properties, Reactions, Occurrences and Uses, Wiley-VCH, Weinheim, edn. 2 (2003).

33. A. Sperlich, Ph.D. Thesis, Phosphate Adsorption onto Granular Ferric Hydroxide (GFH) for Wastewater Reuse, Technische Universität Berlin, Germany (2010).

34. Y.N. Zhu, D.Q. Wang, X.H. Zhang and H.D Qin, Fresenius Environ. Bull., 18, 369 (2009).

35. J. He, S. Hong, L. Zhang, F.X. Gan and Y.-S. Ho, Fresenius Environ. Bull., 19, 2651 (2010).

36. Y.S. Ho and G. McKay, Proc. Saf. Environ. Prot., 76, 332 (1998).

37. S.J. Zhang, X.Y. Li and J.P. Chen, J. Colloid Interf. Sci., 343, 232 (2010).

38. X.Y. Yang, S.R. Otto and B. Al-Duri, Chem. Eng. J., 94, 199 (2003).

39. W.H. Cheung, Y.S. Szeto and G. McKay, Bioresour. Technol., 98, 2897 (2007). 